Hydraulic Engineering Repository

Ein Service der Bundesanstalt für Wasserbau

Zou, Y.; Boley, C.; Wehr, J.

On the Stress Dependent Contact Erosion in Vibro Stone Columns

Verfügbar unter / Available at:

https://hdl.handle.net/20.500.11970/100248

Vorgeschlagene Zitierweise / Suggested citation:

Zou, Y.; Boley, C.; Wehr, J. (2010): On the Stress Dependent Contact Erosion in Vibro Stone Columns. In: Burns, Susan E.; Bhatia, Shobha K.; Avila, Catherine M. C.; Hunt, Beatrice E. (Hg.): Proceedings 5th International Conference on Scour and Erosion (ICSE-5), November 7-10, 2010, San Francisco, USA. Reston, Va.: American Society of Civil Engineers. S. 241-250. 


\title{
On the Stress Dependent Contact Erosion in Vibro Stone Columns
}

\author{
Y. Zou ${ }^{1}$, C. Boley ${ }^{2}$ and J. Wehr ${ }^{3}$
}

${ }^{1}$ Institute for Soil Mechanics and Foundation Engineering, University of the Federal Armed Forces Munich, Werner-Heisenberg-Weg 39, 85577 Neubiberg, Germany; yazhou.zou@unibw.de

${ }_{2}^{2}$ Institute for Soil Mechanics and Foundation Engineering, University of the Federal Armed Forces Munich, Werner-Heisenberg-Weg 39, 85577 Neubiberg, Germany; conrad.boley@unibw.de

${ }^{3}$ Keller Holding GmbH, 63067 Offenbach Germany; j.wehr@kellerholding.com

\begin{abstract}
In order to investigate the hydraulic contact erosion during and after the installation of a stone column, model tests were carried out in the laboratory. Under a critical hydraulic gradient, some fine soil particles in the subsoil around the stone column may be brought into the pore space of the stone column under certain conditions. The critical hydraulic gradient not only depends on the type of stone columns and the fine grained soils around the stone columns, but also on the stress state in the subsoil. Terzaghi's filter criteria (Terzaghi 1948) do not apply to determine the critical hydraulic gradient. For the stone columns with a suitable grain size distribution the hydraulic contact erosion will not occur, and a geotextile cover around the stone column hardly influences the critical hydraulic gradient. The critical hydraulic gradient can be estimated by using present theoretical models.
\end{abstract}

\section{INTRODUCTION}

Vibro replacement stone columns are commonly used to improve saturated soft subsoil which consists mainly of fine grained soils (Kirsch 1979). A cylindrical vibrator penetrates the subsoil to a designed depth at first (Fig. 1a). During the penetration the subsoil consisting of fine grained soils around the vibrator is displaced laterally. Then, a coarse grained material exerting gradually the bottom of the vibrator is compacted by means of lateral vibration of the vibrator from the designed depth to the top of the ground surface (Fig. 1b). Subsequently a stone column made of coarse grained material is constructed in the subsoil (Fig. 1c). The coarse grained material is usually gravel, stone and sand. Through vibration the subsoil made of fine grained soils around the stone column is furthermore displaced laterally. Through the lateral compression a filter zone can be developed and at the same time an excess pore water pressure $\mathrm{u}_{\mathrm{e}}$ occurs in the subsoil around the stone column (Fig, 1d). The measured results in situ have shown that the excess pore water pressure can be up to $35 \mathrm{kN} / \mathrm{m}^{2}$ (Weber 2006). Under the excess pore water pressure $\mathrm{u}_{\mathrm{c}}$ the displaced subsoil begins to drain radially into the stone column (Fig. 1d). The hydraulic gradient and the radial seepage force next to the boundary between the fine grained soil and the stone column can be relatively high at the beginning of the drainage. If the pore size of the stone column is relatively large and the excess pore 
water pressure is very high, the high seepage force may bring the particles of fine grained soil into the pore space of the stone column. That means that hydraulic contact erosion may occur at the boundary between the fine grained soil and the stone column under the condition of a very high excess pore water pressure. The hydraulic contact erosion may lead then to loosening or softening of the subsoil near the contact boundary and thus may reduce the bearing capacity of the stone column (Weber 2006).

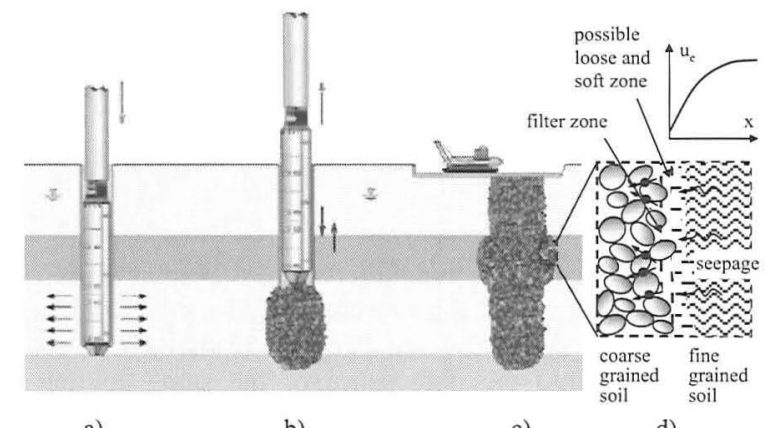

a)

b)

c)

d)

Figure 1. Constructing a stone column and excess pore water pressure $u_{e}$

In order to avoid damage due to hydraulic contact erosion to the subsoil, columns can be surrounded by a geotextile (Raithel et al. 2005). The stone columns surrounded by a geotextile can also be used to improve the soft subsoil which consists of peat or mucky clay (Raithel 2006). The investigations of hydraulic contact erosion have shown that the critical hydraulic gradient of hydraulic contact erosion is dependent not only on the type of soils but also on the stress state at the contact boundary (Zou 1999 and Schmitz 2006).

In order to investigate the failure mechanisms and the critical hydraulic gradient of the hydraulic contact erosion during and after constructing stone columns in different soils with and without surrounding geotextile, model tests were carried out in laboratory. The experimental apparatus and results are reported in this paper. The mechanisms of the hydraulic failure in different soils and the effects of soil types and stress states on the critical hydraulic gradient are analyzed. The critical hydraulic gradients for different soils and under different stress states were estimated with different theoretical models. Some conclusions are made for practical applications.

\section{EXPERIMENTS}

\section{Materials}

Three coarse grained soils G-1 to G-3 were used as the material of the model stone columns for the tests. Their grain size distributions are shown in Figure 2. The grain size of G-1 and G-2 are very uniform. G-3 is a mixture of sand and gravel. Their material parameters, i.e. grain size $d_{17}$ for mass percentage $17 \%$, uniformity 
coefficient $\mathrm{C}_{\mathrm{u}}$, the minimum and maximum void ratio $\mathrm{e}_{\min }$ and $\mathrm{e}_{\max }$ are listed in Table 1. The void ratio $e_{\min }$ and $e_{\max }$ are measured under dry conditions.

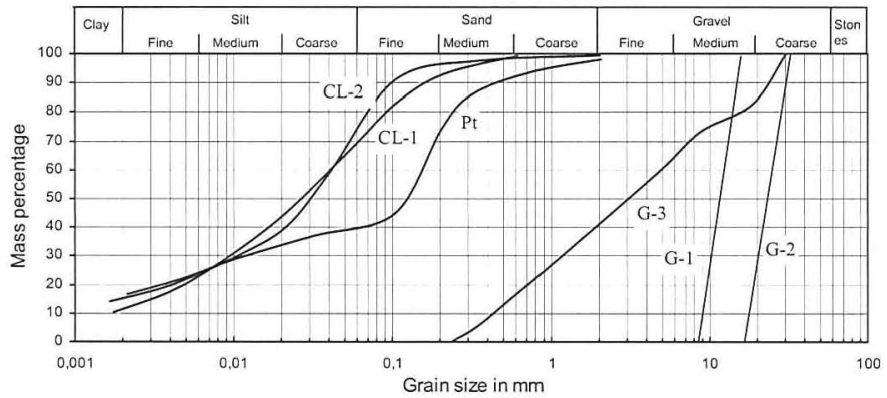

Figure 2. Grain size distribution

Table 1. Material parameters of coarse grained soils

\begin{tabular}{c|c|c|c|c|c|c}
\hline Material & $\mathrm{d}_{17}(\mathrm{~mm})$ & $\mathrm{C}_{\mathbf{u}}(-)$ & $\mathrm{e}_{\max }(-)$ & $\mathbf{e}_{\min }(-)$ & $\mathbf{I}_{\mathbf{D}}(-)$ & $\mathrm{e}(-)$ \\
\hline $\mathrm{G}-1$ & 9 & 1.4 & 0.39 & 0.27 & 0,50 & 0.33 \\
\hline $\mathrm{G}-2$ & 18 & 1.4 & 0.46 & 0.33 & 0,62 & 0.38 \\
\hline $\mathrm{G}-3$ & 0.6 & 12.5 & 0.40 & 0.25 & 0,53 & 0.32 \\
\hline
\end{tabular}

Three fine grained soils CL-1, Pt and CL-2 are used as fine grained soils around the model stone columns for the tests. Their grain size distributions are also shown in Figure 2. According to USCS classification they are called inorganic clays of low plasticity (CL-1), peat $(\mathrm{Pt})$ and inorganic clays of low plasticity (CL-2). The organic content in the peat $(\mathrm{Pt})$ is very high. Their material parameters, i.e. liquid limit $\mathrm{w}_{\mathrm{L}}$, plastic limit $\mathrm{w}_{\mathrm{P}}$, organic content $\mathrm{V}_{\text {org }}$, effective cohesion $\mathrm{c}^{\prime}$ and effective angle of friction $\varphi^{\prime}$ base on direct shear tests are listed in Table 2 . The liquid limit $w_{L}$ and plastic limit $W_{P}$ of the peat are very high. After the early research results (Zou 1999 and Schmitz 2006) the critical hydraulic gradient of hydraulic contact erosion depends primarily on the strength of the fine grained soil, on the size of the coarse grained soil and on the stress state in the fine grained soil. Therefore, the details on fine grained fabric are not reported in this paper as important content.

Table 2. Material parameters of fine grained soils

\begin{tabular}{c|c|c|c|c|c}
\hline Material & $\mathbf{w}_{\mathbf{L}}(\boldsymbol{\%})$ & $\mathbf{w}_{\mathbf{P}}(\boldsymbol{\%})$ & $\mathbf{V}_{\text {org }}(\%)$ & $\mathbf{c}^{\prime}\left(\mathbf{k N} / \mathbf{m}^{2}\right)$ & $\varphi^{\prime}\left({ }^{\circ}\right)$ \\
\hline $\mathrm{CL}-1$ & 27 & 16 & $<1$ & 7.2 & 31 \\
\hline $\mathrm{Pt}$ & 156 & 78 & 25 & 12 & 20 \\
\hline $\mathrm{CL}-2$ & 41 & 15 & 3 & 7.5 & 31 \\
\hline
\end{tabular}

The geotextile Type 100/200 from the company HUESKER was used as cover surrounding the model stone columns. The effective opening size of the 
geotextile is $\mathrm{O}_{90}=0.2 \mathrm{~mm}$. The water flow velocity through the geotextile under the water pressure head $\mathrm{H}_{\mathrm{w}}=50 \mathrm{~m}$ is $\mathrm{v}_{\mathrm{H} 50}=5 \cdot 10^{-3} \mathrm{~m} / \mathrm{s}$.

\section{Experimental apparatus and procedures}

All tests were carried out in a specially designed model box (Figure 3). The front wall of the model box consists of Plexiglas. The coarse grained soil 1 to model a stone column was constructed in the middle of the saturated fine grained soil 2 which models the soils around stone columns in situ. The model stone column can be surrounded by geotextile (GT) or without geotextile. Above and below the saturated fine grained soil two clay layers 3 were laid as a sealing. Both the coarse and saturated fine grained soils can be loaded by a pressurized air cushion 4 under the pressure $\sigma_{v}$ vertically. Under the pressure p the water in the tank 5 can flow through the entrance tube 6 , porous plate 7 and the pore space of the saturated fine grained soil 2 and the stone column 1, and then through the perforated plate 8 into the sedimentation tank 9. Afterwards it flows out through the output tube 10. The fine soil particles washed out are deposited in the sedimentation tank 9. The vertical pressure (stress) $\sigma_{\mathrm{v}}$ in air cushion 4 and the pressure $\mathrm{p}$ in the water tank 5 can be regulated. The length $\mathrm{L}$ of flow lines in the fine grained soil 2 is known. With the pressure $p$, the length $L$ und the unit weight $\gamma_{w}$ of water the hydraulic gradient $i=$ $\mathrm{p} /\left(\mathrm{L} \cdot \gamma_{\mathrm{w}}\right)$ in the fine grained soil 2 can be calculated. Prior to testing the fine grained soil 2 was saturated.

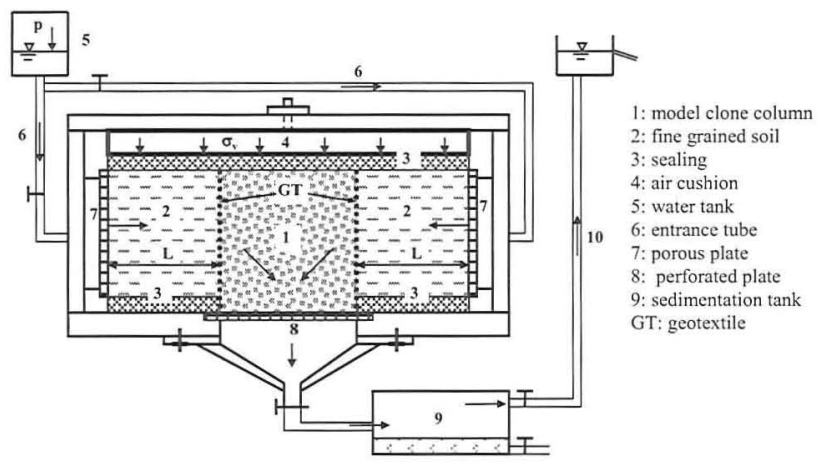

Figure 3. Experimental apparatus

Under a constant vertical stress $\sigma_{v}$ the pressure $\mathrm{p}$ in the water tank 5 , and the hydraulic gradient $\mathrm{i}$ can be increased stepwise. The interval of a pressure increase is approx. 10 hours. The dry mass $m_{d}$ of the fine soil particles deposited in the tank 9 can be determined depending hydraulic gradient $i$. The discharge $q$ depends on hydraulic gradient $i$ and can be determined by measuring the water volume $\Delta V_{w}$ flowing through the saturated fine grained soil. If under the pressure $p=p_{c r}$ for a constant pressure $\sigma_{\mathrm{v}}$ a hydraulic fracture occurs, i.e. a continuous flow canal has been formed in the fine grained soil, the discharge $q$ (or the water volume $\Delta V_{w}$ ) 
increases evidently and a large amount of fine soil particles are brought into the void space of the model stone column, and the corresponding hydraulic gradient is defined as critical hydraulic gradient $i_{\text {cr }}$.

Under different pressures $\sigma_{v}$ and with different soil materials as model stone columns and as fine grained soils around the model stone columns, 19 model tests were carried out in laboratory. The vertical stress $\sigma_{\mathrm{v}}$, the length $\mathrm{L}$ of flow lines in the fine grained soil, the coarse grained materials and the fine grained soils for the 19 model tests are listed in table 3 . The relative density $I_{D}$ and the void ratio e of the model stone columns for the tests are shown in table 1 .

Table 3. Test program and critical hydraulic gradient

\begin{tabular}{|c|c|c|c|c|c|c|}
\hline $\begin{array}{l}\text { Test- } \\
\text { No. }\end{array}$ & $\begin{array}{l}\text { Stone } \\
\text { column }\end{array}$ & $\begin{array}{c}\text { Fine } \\
\text { grained } \\
\text { soils }\end{array}$ & $\begin{array}{l}\text { Vertical } \\
\text { stress } \sigma_{v} \\
\left(\mathrm{kN} / \mathrm{m}^{2}\right)\end{array}$ & $\begin{array}{c}\text { With } \\
\text { Geotextile }\end{array}$ & $\begin{array}{c}\mathrm{L} \\
(\mathrm{cm})\end{array}$ & $\begin{array}{c}\text { Critical } \\
\text { hydraulic } \\
\text { gradient } i_{\mathrm{cr}}\end{array}$ \\
\hline $1 / 2$ & \multirow{5}{*}{$\mathrm{G}-1 / \mathrm{G}-2$} & \multirow{6}{*}{ CL-1 } & 30 & \multirow{6}{*}{ No } & 16 & $15 / 15$ \\
\hline $3 / 4$ & & & 60 & & 16 & $35 / 35$ \\
\hline $5 / 6$ & & & 90 & & 16 & $53 / 53$ \\
\hline $7 / 8$ & & & 120 & & 16 & $70 / 60$ \\
\hline $9 / 10$ & & & 150 & & 16 & $90 / 80$ \\
\hline 11 & G-1 & & 180 & & 16 & 110 \\
\hline $12 / 13$ & \multirow{4}{*}{ G-3 } & \multirow{3}{*}{ CL-2 } & 60 & No/Yes & 10 & $55 / 45$ \\
\hline $14 / 15$ & & & 90 & No/Yes & 10 & $75 / 75$ \\
\hline $16 / 17$ & & & 120 & No/Yes & 10 & $85 / 85$ \\
\hline $18 / 19$ & & $\mathrm{Pt}$ & 60 & No/Yes & 10 & $55 />55$ \\
\hline
\end{tabular}

\section{OBSERVATIONS AND EXPERIMENTAL RESULTS}

\section{Observations}

When the pressure $\mathrm{p}$ in the water tank 5 which corresponds to the hydraulic gradient, was relatively low, seepage occurred in the fine grained soil, but none or only a few of fine soil particles have been brought into the pore space of the stone column. With the increase of hydraulic gradient more and more fine soil particles were seen in the pore space of the stone column (Figure 4). When the pressure p in the water tank 5 was relatively high or near the vertical stress $\sigma_{\mathrm{v}}$, a continuous flow canal was formed in the fine grained soil, and a large amount of fine soil particles have been brought into the pore space of the stone column. Figure 4 shows the proof of an eroded flow canal. The corresponding hydraulic gradient is the critical hydraulic gradient $i_{\text {cr }}$ named above.

\section{Experimental results}

The increase of the dry mass $m_{d}$ of the fine soil particles deposited in the tank 9 with increasing hydraulic gradient $i$ for tests 5 and 6 is shown in Figure 5, for example. Because the dry mass $m_{d}$ deposited in the tank 9 is very low in relation to the total original mass which depends also on the height and width of the fine grained 
soil, a normalized dry mass by the total original mass is not important. At first the dry mass $m_{d}$ increases linearly with the hydraulic gradient. Just below the hydraulic gradient $i_{c r}$ the dry mass $m_{d}$ increases very evidently. This means that a large amount of fine grained soil has been washed away at the hydraulic gradient $i_{\mathrm{cr}}$. The variations of discharge q with increasing hydraulic gradient $i$ for tests 5 and 6 are also shown in Figure 5. The discharge $\mathrm{q}$ also increases linearly with the hydraulic gradient. At the same hydraulic gradient $i_{c r}$ the discharge $q$ suddenly becomes very high. This means that a continuous flow canal has been formed in the fine grained soil. This hydraulic gradient $i_{c r}$ is the critical hydraulic gradient. It is very clear that just below the critical hydraulic gradient $i_{\text {cr }}$ a continuous flow canal (no flow path) has been formed.

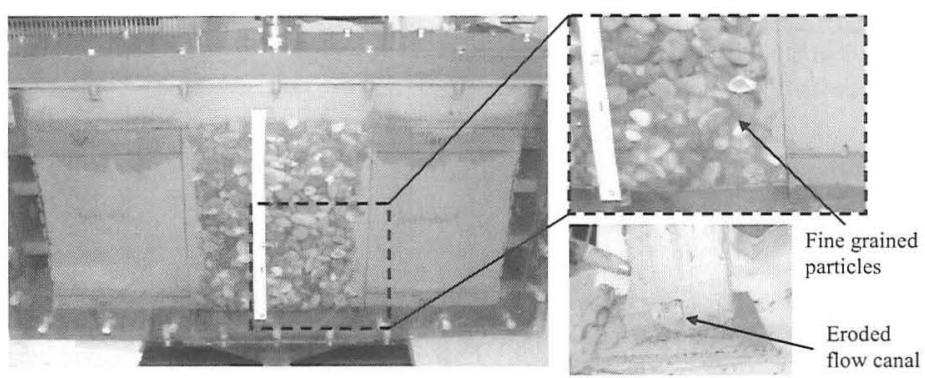

Figure 4. Fine soil particles in the stone column and eroded flow canal
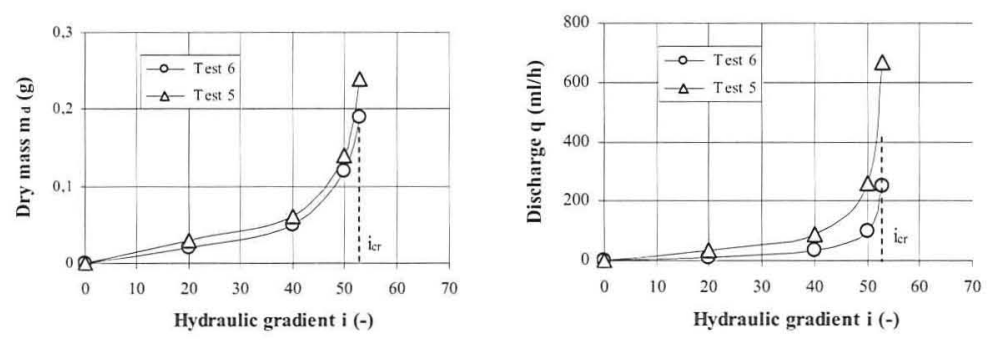

Figure 5. Dry mass $m_{d}$ and discharge $q$ depending on the hydraulic gradient $i$

The critical hydraulic gradients $i_{\text {cr }}$ of the tests are listed in tables 3 and 4 . The dependence of the critical hydraulic gradient $i_{\text {cr }}$ on the vertical stress $\sigma_{v}$ for different stone column materials (coarse grained soils) and for different fine grained soils, with and without geotextile, are shown in Figures 6. Below a low vertical stress $\sigma_{\mathrm{vc}}$, e.g. $\sigma_{\mathrm{v}}<\sigma_{\mathrm{vc}}=80 \mathrm{kN} / \mathrm{m}^{2}$, the critical hydraulic gradient $\mathrm{i}_{\mathrm{cr}}$ increases linearly with the vertical stress $\sigma_{v}$, and for the same fine grained soil the critical hydraulic gradient $i_{c r}$ is independent of the material of stone columns. In this case, the pressure $p$ in the water tank 5 , corresponding to $i_{\text {cr }}$ has always been near to the vertical stress $\sigma_{\mathrm{v}}$. The vertical effective stress in the fine grained soil was equal to zero approximately. That means that a continuous flow canal will occur if the pore water pressure is equal to 
the vertical stress $\sigma_{v}$. Therefore, the hydraulic gradient corresponding to the vertical stress $\sigma_{v}$ is an upper boundary of the critical hydraulic gradient.

\section{Table 4. Critical hydraulic gradient}

\begin{tabular}{l|c|c|c|c|c|c|c|c|c|c}
\hline Test-No. & $1 / 2$ & $3 / 4$ & $5 / 6$ & $7 / 8$ & $9 / 10$ & 11 & $12 / 13$ & $14 / 15$ & $16 / 17$ & $18 / 19$ \\
\hline $\mathrm{i}_{\text {cr }}(-)$ & $15 / 15$ & $35 / 35$ & $53 / 53$ & $70 / 60$ & $90 / 80$ & 110 & $55 / 45$ & $75 / 75$ & $85 / 85$ & $55 />55$ \\
\hline
\end{tabular}

Above a relatively high vertical stress $\sigma_{v c}$, e.g. $\sigma_{v}>\sigma_{v c}=80 \mathrm{kN} / \mathrm{m}^{2}$, the dependence of the critical hydraulic gradient $i_{\text {cr }}$ on the vertical stress $\sigma_{v}$ deviates from the linear relation (Figure 6). In this case, the critical hydraulic gradient $i_{\text {cr }}$ is lower than the upper boundary. Under the same vertical stress $\sigma_{v}>\sigma_{v c}$ the critical hydraulic gradient $i_{\text {cr }}$ is different for different coarse grained soils (Figure 6 a). The finer the materials of stone columns are for the same fine grained soil, the higher is the critical hydraulic gradient $i_{\text {cr. }}$. After the early research results (Rehfeld 1967, Zou 1999 and Schmitz 2006) the critical hydraulic gradient $i_{\text {cr }}$ depends on the pore size of coarse grained soils. The larger the pore size, the lower is the critical hydraulic gradient $\mathrm{i}_{\mathrm{cr}}$. The grain size of G2 is larger than the grain size of G1. The pore size of the G2 is larger than the pore size of G1. Therefore, the critical hydraulic gradient $i_{\text {cr }}$ of the stone columns G2 is lower than that of the stone columns G1. Particularly, the larger the pore size of coarse grained soils, the lower is the critical vertical stress $\sigma_{\mathrm{vc}}$. More details on the influence of the pore size on the critical hydraulic gradient $i_{\text {cr }}$ and its physical mechanisms were reported by Rehfeld 1967, Zou 1999 and Schmitz 2006.

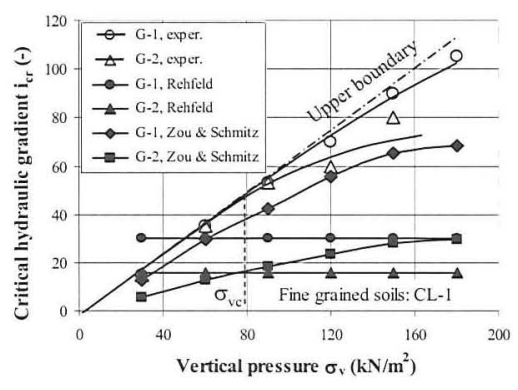

a)

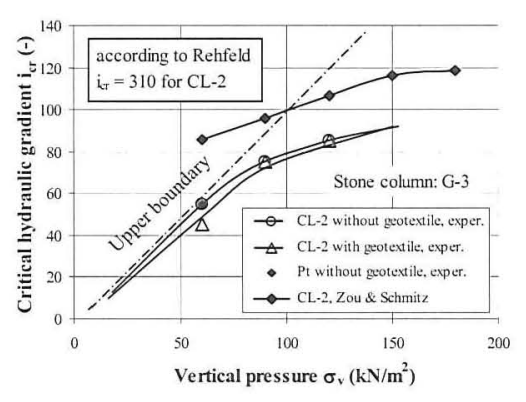

b)

Figure 6. Dependence of critical hydraulic gradient $i_{c r}$ on vertical stress $\sigma_{v}$

Using G-3 (a mixture of sand and gravel) as the material of the model stone column, the critical hydraulic gradient $i_{\text {cr }}$ with and without geotextile is almost identical (Figure 6 b). This means that, in this case, the geotextile surrounding the column does not influence the critical hydraulic gradient $\mathrm{i}_{\mathrm{cr}}$. If the critical hydraulic gradient $i_{\text {cr }}$ is near the upper boundary, the critical hydraulic gradient is also independent on the type of fine grained soils by using G-3 as the material of the model stone column. 
The experimental results have indicated that the critical hydraulic gradient $i_{c r}$ also depends on the length $\mathrm{L}$ of the flow lines. More research in that area will be necessary to clarify the details.

\section{THEORETICAL ESTIMATION}

In order to estimate critical hydraulic gradients $i_{\text {cr }}$, Rehfeld 1967 proposed the theoretical equation (1):

$$
i_{c r}=\frac{c^{\prime}}{4.4 \cdot d_{p} \cdot \gamma_{w} \cdot \tan \varphi^{\prime}}
$$

Where $d_{p}$ is the so-called equivalent pore diameter of the coarse grained soil (stone column) and can be calculated with equation (2):

$$
d_{p}=0.535 \cdot \sqrt[6]{C_{u}} \cdot e \cdot d_{17}
$$

By using the theoretical equations (1) and (2) after Rehfeld 1967 as well as the parameters listed in tables 1 and 2 the critical hydraulic gradients $i_{\mathrm{cr}}$ are calculated and shown in Figures 6, in comparison with the experimental results. Because in the theoretical equation (1) the influence of stress state was not considered, the calculated critical hydraulic gradient is independent of the vertical stress $\sigma_{\mathrm{v}}$. For stone columns G-1 and G-2 and for the fine grained soil CL-1 the calculated critical gradient $i_{c r}$ is lower than the experimental results for $\sigma_{v}>30$ and $50 \mathrm{kN} / \mathrm{m}^{2}$ respectively (Figure 6 a). For stone column G-3 and for the fine grained soil CL-2 the calculated critical gradient is much higher than the experimental results (Figure $6 \mathrm{~b}$ ). The discrepancy between the experimental data and theoretical results may be primarily due to neglecting the influence of stress state. The strength parameters $c^{\prime}$ and $\varphi^{\prime}$, the model parameter $d_{p}$ and the model assumption of Rehfeld 1967 may influence the theoretical results.

In order to estimate the critical hydraulic gradient $i_{\text {cr }}$ depending on the vertical stress $\sigma_{v}$, Zou 1999 proposed the equation (3):

$$
i_{c r}=\frac{2 c^{\prime}-\left(\zeta-\xi \cdot \tan \varphi^{\prime}\right) \cdot \sigma_{v}}{0.5 \cdot d_{p} \cdot \gamma_{w} \cdot\left(1+\xi_{0} \cdot \tan \varphi^{\prime}\right)}
$$

Schmitz 2006 has determined the dependence of the parameters $\xi_{0}$ and $\zeta$ in equation (3) on the vertical stress $\sigma_{v}$ by means of numerical calculations and proposed that the value of the parameter $\xi$ in equation (3) should be between 0.2 and 0.6 . Using equations (3) and (2), with the parameters in tables 1 and 2 as well as with $\xi=0.46$ the critical hydraulic gradients $i_{\mathrm{cr}}$ depending on the vertical stress $\sigma_{\mathrm{v}}$ are calculated, where the parameters $\xi_{0}$ and $\zeta$ depending on the vertical stress $\sigma_{\mathrm{v}}$ are determined according to Schmitz 2006 and are shown in Figure 7. 


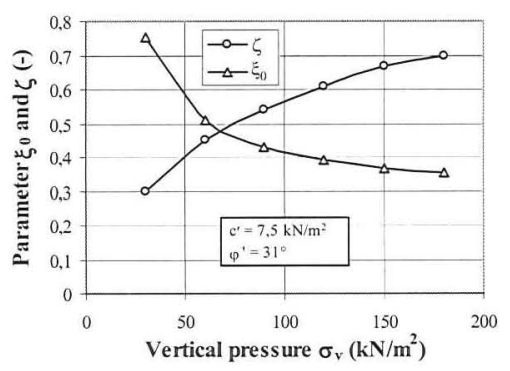

Figure 7. Parameters $\xi_{0}$ and $\zeta$ in dependence on vertical stress $\sigma_{v}$

The calculated critical hydraulic gradients $i_{\text {cr }}$ are shown in Figures 6 , in comparison with the experimental results. The calculated critical hydraulic gradient $i_{\text {cr }}$ according to Zou and Schmitz depends on the vertical stress $\sigma_{v}$. For stone column G-1 and G-2 and for the fine grained soil CL-1 the calculated critical gradient $i_{\text {cr }}$ is lower than the experimental results (Figure 6 a). For stone column G-3 and for the fine grained soil CL-2 the calculated critical gradient is higher than the experimental results (Figure $6 \mathrm{~b}$ ). The discrepancy between the experimental data and theoretical results may be primarily due to material and model parameters.

To estimate the critical hydraulic gradient accurately, the parameter in tables 1 and 2 as well as the parameters $\xi_{0}$ and $\zeta$ in equation (3) must be determined reasonably.

\section{CONCLUSIONS}

Terzaghi's filter criteria (Terzaghi 1948) are geometric criteria. Therefore they do not apply to determine the critical hydraulic gradient.

If the excess pore water pressure occurring during the installation of a stone column is very high, the dissipation of the excess pore water pressure may theoretically cause a process of fine grained soil around the stone column moving into the pore space of the stone column. The higher the excess pore water pressure is, the more fine soil particles are brought into the pore space of stone columns. Under a very high excess pore water pressure, a continuous flow canal may occur. Thus, hydraulic contact erosion may occur at the boundary between the fine grained soil and the stone column. Within our investigations it is checked whether the above mentioned processes can occur under conditions of practical relevance.

The critical hydraulic gradient of the hydraulic contact erosion not only depends on the materials of stone columns and the fine grained soil around the stone columns, but also on the stress state in the subsoil. The larger the pore size of the stone column, the lower is the critical hydraulic gradient. The higher the shear strength and the stress of the fine grained soil, the higher is the critical hydraulic gradient. For a relatively low stress in the subsoil the critical hydraulic gradient is corresponding to the vertical stress $\sigma_{v}$ in the subsoil. If the excess pore water pressure in the subsoil is near the vertical stress $\sigma_{\mathrm{v}}$, the hydraulic contact erosion may 
occur. For relatively high stresses in the subsoil, the water pressure corresponding to the critical hydraulic gradient is lower than the vertical stress $\sigma_{\mathrm{v}}$ in the subsoil.

The measured results in situ have shown that the excess pore water pressure is not very high (Weber 2006). If the grain size distribution of stone columns is well graded, the strength of the fine grained soils is relatively high and thus hydraulic contact erosion will not occur in the subsoil surrounding the stone column.

If the material of stone columns has a suitable grain size distribution, e.g. well graded, a geotextile surrounding the stone column hardly influences the critical hydraulic gradient $\mathrm{i}_{\mathrm{cr}}$.

The critical hydraulic gradient for the hydraulic contact erosion can be estimated using the theoretical equation (1) or (3) approximately. For an accurate estimate of the critical hydraulic gradient, reasonable determination of the model and soil parameters in equation (1) and (3) is necessary.

So far our investigations have shown that contact erosion of soil surrounding vibro stone columns has no significant influence for a wide variety of conditions in situ.

\section{REFFERENCES}

Kirsch, K. (1979). “Erfahrungen mit der Baugrundverbesserung durch Tiefenrüttler. "Geotechnik 2, 1979, 21-32.

Raithel, M., Kempfert, H.G. and Kirchner, A. (2005). "Berechnungsverfahren und Bemessung von ummantelten Säulen - Entwicklung und aktueller Stand." Geotechnik 1, 2005, 20-31.

Raithel, M. (2006), "Ummantelte Säulen zur Gründung von Bauwerken auf weichen Böden." Ummantelte Säulen der EBGEO.

Rehfeld, E. (1967). "Die Erosionsbeständigkeit bindiger Lockergesteine - die wichtige Grundlage zur Dimensionierung von Dichtungsschichten aus natürlichen Erdstoffen." Wissenschaftliche Zeitschrift der Technischen Universität Dresden, Heft 5, 16.

Schmitz, S., Boley, C. and Zou, Y. (2006). "Stress dependent erosion in layered soil." First Mediterranean Symposium on Advances in Geomaterials and Structures in Hammamet, Tunesien, S. 147 - 152.

Schmitz, S. (2007). "Zur hydraulischen Kontakterosion bei bindigen Basiserdstoffen." Mitteilungen des Institutes für Bodenmechanik und Grundbau, Universität der Bundeswehr München, Heft 19.

Terzaghi, K. \& Peck, R. (1948). „Soil mechanics in engineering practice. John Wiley and Sons Inc. New York.

Weber, T.M. (2006). "Centrifuge modeling and testing of stone columns." Professorship for Geotechnical Engineering, $2^{\text {nd }}$ AMGISS School \& Workshop, ETH Zurich, 11-14 Sep. 2006.

Zou, Y. (1999). "Der vom Spannungszustand und Bodengefüge abhängige Erosionsdurchbruch bindiger Böden.“ Wasserwirtschaft, Nr. 11, S. 554 - 559. 